\title{
ARABE-BARBE HORSE'S SPERM MOTILITY IMPROVEMENT USING HONEY
}

\author{
Mohamed Amine Ayad', Mohamed Said Saim', Samia Meliani²*, Fatima Zohra Demni', Sofiane Derrar ${ }^{1}$ \\ ${ }^{1}$ The Veterinary Sciences Institut, Ibn Khaldoun University of Tiaret, 14000, Algeria; \\ ${ }^{2}$ Nature and life sciences faculty, Ibn Khaldoun University of Tiaret, 14000, Algeria; \\ *Corresponding Author Samia Meliani, email: meianisamia@ hotmail.com;
}

Received September 2019; Accepted October 2019; Published November 2019;

DOI: https://doi.org/10.31407/ijees9426

\begin{abstract}
The aim of this study was to evaluate the effect of extender supplementation with different concentrations of Algerian honey on post-thawed sperm motility, and viability. Sperm samples collected from Arabe-Barbe staillons were subjected to cryopreservation with a modified Kenney, without any supplementation (control) or supplemented with $1 \%, 2 \%, 3 \%, 4 \%$ and $5 \%$ of Algerian honey. After thawing, all samples were maintained at $37{ }^{\circ} \mathrm{C}$, while analyses were performed at $0,30^{\prime}, 60^{\prime}$ and $120^{\prime}$. Sperm motility percentage, and viability index percentage, of each sample were determined by conventional laboratory methods. Compared to the control group, supplementation with Algerian honey (2\% and 3\% significantly improved post-thaw sperm motility, at 0, 30', 60' and 120'. For all semen parameters, the lower concentration of honey (1\%) and higher concentration (4\% and 5\%) did not show any significant differences compared with the control. These works showed that extender supplementation with Algerian honey provided a good protection of sperm parameters against cryopreservation injury, in comparison to the control groups.
\end{abstract}

Keywords: Arab-Barbe, Semen, cryopreservation, Honey, Motility. 